\title{
Recerca geològica i mineralògica per la comarca del Pallars Sobirà: des del Pont de Bresca i Gerri de la Sal a Baro, Montardit i a Sort
}

Josep Maria Mata-Perelló

Joaquim Sanz Balagué

\section{XARAGALL \\ REVISTA DE CIÈNCIES DE LA CATALUNYA CENTRAL} n. 7

JULIOL 2015 


\title{
RECERCA GEOLÒGICA I MINERALÒGICA PER LA COMARCA DEL PALLARS SOBIRÀ: DES DEL PONT DE BRESCA I GERRI DE LA SAL A BARO, MONTARDIT I A SORT
}

\author{
Josep Maria Mata-Perelló \\ Museu de geologia Valentí Masachs, Escola Politècnica Superior d'Enginyeria de Manresa \\ (EPSEM), Universitat Politècnica de Catalunya · BarcelonaTech (UPC), 08272 Manresa, Spain
}

\section{Joaquim Sanz Balagué}

Departament d'Enginyeria Minera i Recursos Naturals (EMRN), Escola Politècnica Superior d'Enginyeria de Manresa (EPSEM), Universitat Politècnica de Catalunya . BarcelonaTech (UPC), 08272 Manresa, Spain

Paraules clau: Sistema Pirinenc, Patrimoni miner

\section{Resum}

Itinerari realitzat el 14 de juliol de 2014. En aquesta ocasió, la totalitat del recorregut de I'itinerari discorrerà pel Sistema Pirinenc. Així, en tot el recorregut, ho farà per la Unitat del Mantell de les Nogueres (la qual forma part de les tradicionalment anomenades Serres Exteriors Prepirinenques). No s'arribarà a entrar, en cap moment en els Apilaments Antiformes de la Zona Axial Pirinenca, que quedaran al Nord d'aquest recorregut.

Per d'altra banda, el recorregut de l'itinerari discorrerà íntegrament per una sola comarca, concretament per la del Pallars Sobirà (encara que començarà prop del Pallars Jussà), situada dintre de la Regió de Tremp (o de Tremp-Seu d’Urgell). 


\section{Objectius fonamentals}

Es centraran en els aspectes geològics, geomorfològics i mineralògics que apuntarem a continuació:

1. Estudi de les estructures més meridionals de la Unitat del Mantell de les Nogueres, situada al Nord del Mantell de Boixols. El recorregut de I'itinerari transitarà per aquesta unitat al llarg de tot el recorregut de l'itinerari, entre el Pont de Bresca i la població de Sort, per on acabarà.

2. Observació i descripció dels materials mesozoics (els quals pertanyen al Triàsic, exclusivament) i dels paleozoics (del Devonià, Carbonífer i del Permià, principalment), que constitueixen la Unitat del Mantell de les Nogueres, i que tallarem pels indrets esmentats al paràgraf anterior. En alguns indrets, al principi del recorregut els podem trobar parcialment recoberts per materials detrítics oligocènics, de caràcter postorogènic.

3. Estudi, a distancia (i si s'escau) de les relacions existents entre les dues sotsunitats esmentades: entre el Mantell de Boixols (de la Unitat Sud-pirinenca Central), i la Unitat del Mantell de les Nogueres. Tot i que per la primera no es transitarà en cap moment.

4. Observació a distancia del sector corresponent als Apilaments Antiformes de la Zona Axial Pirinenca, que quedarà al Nord del recorregut de l'itinerari.

5. Observació, a distancia i si s'escau de les relacions existents entre la Unitat del Mantell de les Nogueres i la Unitat dels Apilaments de la Zona Axial Pirinenca

6. Reconeixement de diverses mineralitzacions situades al llarg del recorregut del present itinerari, com les següents (d'acord amb el recorregut de l’itinerari):

6A) de les mineralitzacions evaporítiques d'HALITA, situades al terme de Gerri de la Sal., entre els materials del Keuper. Es troben dintre de la Unitat del Mantell de les Nogueres.

6B) de les mineralitzacions d'EPIDOTA, relacionades amb roques ofitíques. Es troben a la Bàstida de Sort, dintre de la Unitat del Mantell de les Nogueres.

7. Observació de les explotacions mineres relacionades amb les mineralitzacions esmentades a l'apartat anterior.

8. Observació, si s'escau, de les repercussions sobre el Medi Natural (i sobre el Medi Ambient) provocades per les explotacions mineres, i també pels vials de comunicació.

9. Observació dels diferents indrets relacionats amb el Patrimoni Miner i Geològic, que anirem trobant al llarg del present itinerari. 


\section{Antecedents}

Pel que fa al recorregut d'aquest itinerari, en la seva primera part (entre Gerri de la Sal i Rialb de Noguera), hi ha diversos antecedents nostres, publicat els darrers anys. Entre ells, farem esment dels següents: MATA-PERELLÓ (1995a, 1995b, 1996a, 1996b, 1996c, 1996d, 1998 i 2002, 2009a, 2009b i 2012). També, en farem d'un altre treball en part nostre: MATAPERELLÓ i SANZ (1993).

Pel que fa a les mineralitzacions que veurem en aquest itinerari, cal dir que també ja estat prèviament descrites per nosaltres en MATA-PERELLÓ (1991). En aquest treball es fa referència a les mineralitzacions catalanes en general, parlant-se també de les situades al llarg d'aquest itinerari.

I pel que fa a l'estructura geològica, ens remetem al treball de RIBA et altri (1976), i al de GUIMERÀ et altri (1992). En ambdós, es fa referència a l'estructura geològica dels Països Catalans. Per d'altra banda, també ens remetem a SGC (1990).

Finalment, cal dir que tots aquests treballs, es trobaran relacionats, per estricte ordre alfabètic, dintre de l'apartat dedicat a les REFERĖNCIES BIBLIOGRÀFIQUES, al qual es remetem, pel que s'escaigui.

\section{Recorregut de l'itinerari}

El recorregut del present itinerari s'iniciarà per les immediacions de Gerri de la Sal, a la carretera comarcal C-13 (que aquí és també la N-260). Pels voltants de la població esmentada es realitzaran dues aturades.

I des d'aquí, el recorregut es dirigirà cap al Nord, tot seguint la carretera N-260 / C-13. Així, és passarà per Baró i per la Ribera de Montardit (Montardit de Baix), arribant-se tot seguit a Sort, per on s'efectuarà una nova aturada. En arribar a aquesta població, finalitzarà aquest itinerari.

\section{Advertiments previs}

Com en altres recorreguts de RECERCA GEOLÒGICA I MINERALÒGICA ..., si es disposa del temps suficient, poden efectuar-se passant per totes les parades i filloles. En cas contrari, recomanem prescindir de les anomenades PARADES - CONDICIONALS.

En aquest itinerari, cal tenir força cura del coneixement sobre l'estat de les pistes de muntanya. Així, cal cercar la convenient informació abans de començar el recorregut. En aquest cas, hi ha alguns trams susceptibles de trobar-se en mal estat de conservació.

Per altra banda, i com de costum, recomanem tenir el màxim respecte per la natura, tant al llarg d'aquest recorregut, com en qualsevol moment, al marge d'ell. 


\section{Descripció de l'itinerari}

En aquest recorregut hem situat, com ja és habitual en tots els itineraris, una sèrie d'ESTACIONS o de PARADES, que anirem veient a continuació. En cada cas, els hi donarem una denominació que podrà correspondre a algun paratge proper. També indicarem el terme municipal i la comarca on es troba.

Per altra banda, en cadascuna de les parades, indicarem entre parèntesi el número del "Mapa Topográfico" (de I'Instituto Grográfico y Catastral de España), a escala 1:50.000, on es troba situada la parada considerada. En aquesta ocasió serà algú dels tres fulls següents: 214 (o de Sort) i 252 (o de Tremp).

Així doncs, la relació de les parades ordenades, que constitueixen aquest itinerari, és la següent:

\subsection{Parada 1. SALINES DE GERRI DE LA SAL (antic terme de Gerri de la Sal, i actualment del de Gerri de la Sal - Baix Pallars, comarca del Pallars Sobirà). (Full 252).}

El recorregut de l'itinerari el començarem al Pont de Bresca, tot i que farem un curt recorregut d'uns $4 \mathrm{Km}$, fins a Gerri de la Sal. En arribar a la primera població esmentada, ens caldrà fer la primera de les aturades, a les antigues Salines de Gerri de la Sal. Així, des de I'inici, haurem recorregut poc més de $4 \mathrm{Km}$.

Tot el recorregut realitzat pels voltants de Gerri de la Sal, s'efectua per entre afloraments de nivells guixosos i argilosos, que pertanyen al Triàsic Superior (al Keuper), sempre dintre del Mantell de la Unitat de les Nogueres, que no hem deixat en cap moment del recorregut.

En aquest lloc, a la zona septentrional del poble, es troben una sèrie de salines recuperades, on es pot beneficiar I'HALITA. Aquest mineral ha estat prèviament dissolt per les aigües que han circulat a través dels materials del Keuper. Després, en estancar-se en unes basses, s'evapora l'aigua i es precipita la sal.

Cal dir, que aquestes salines són solament una petitíssima part de les que hi havia a Gerri de la Sal, abans de que els aiguats de l'any 1987 les malmetessin. La situació actual de bona part de les salines es la de trobar-se recobertes per sediments fluvials molt recents.

Malgrat això, abans de la riuada, la seva imatge era aquesta que es pot veure a la fotografia següent. (fotografia 1). 


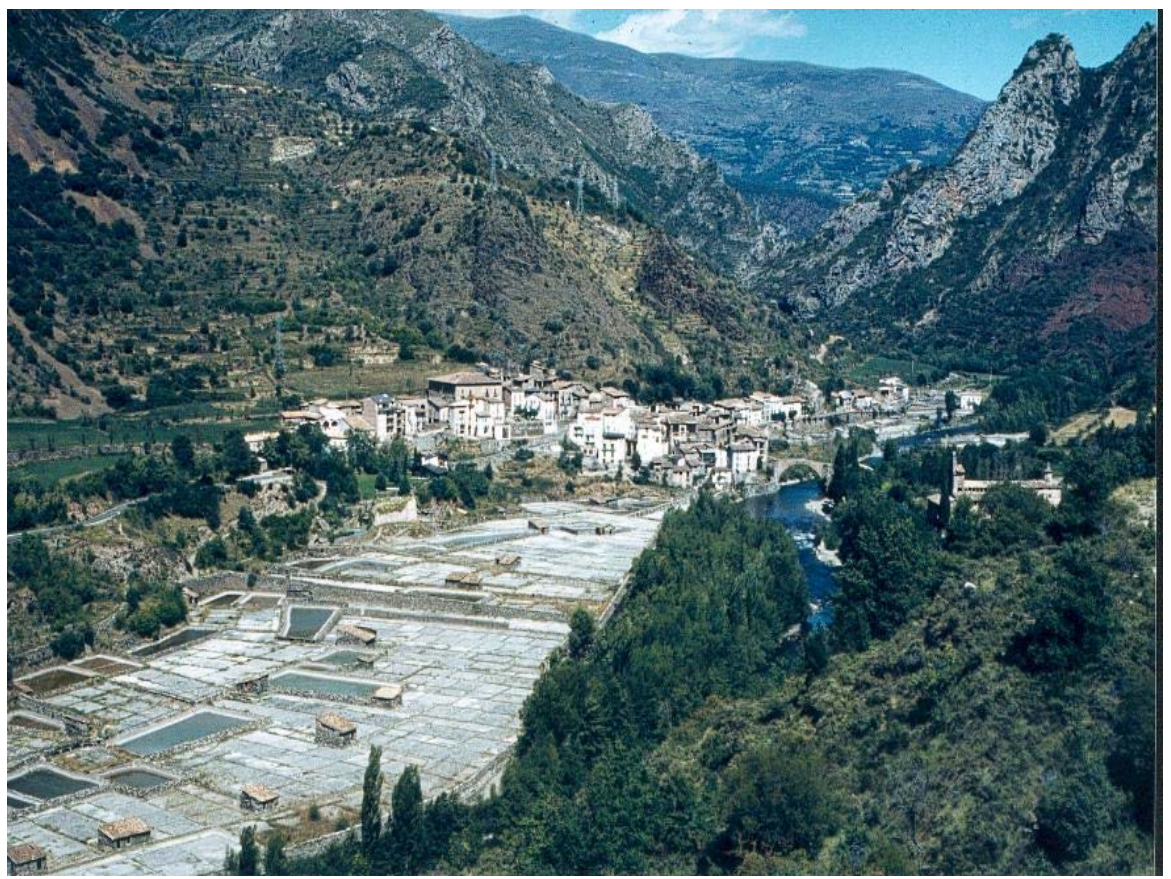

Fotografia 1. Les salines de Gerri de la Sal, abans de la riuada de l'any 1987

Posteriorment, es van malmetre altra part de les salines en fer unes obres de reforma i millora e la zona. Tot i això, encara hi ha una part important de les salines que es pot visitar i està oberta al turisme.

Tot i això, la part perduda, per diferents raons es considerable, ja que les salines s'estenien fins a les immediacions del Pont de Bresca. Per altra banda, entorn a la població de Gerri de la Sal, les salines es trobaven als dos cantons del riu Pallaresa.

Un indret interessant del patrimoni miner d'aquest conjunt, el constitueix l'edifici de I'anomenada Lonja de la Sal. Aquest edifici es troba situat al bell mig de la població de Gerri de la Sal. (fotografia 2). 


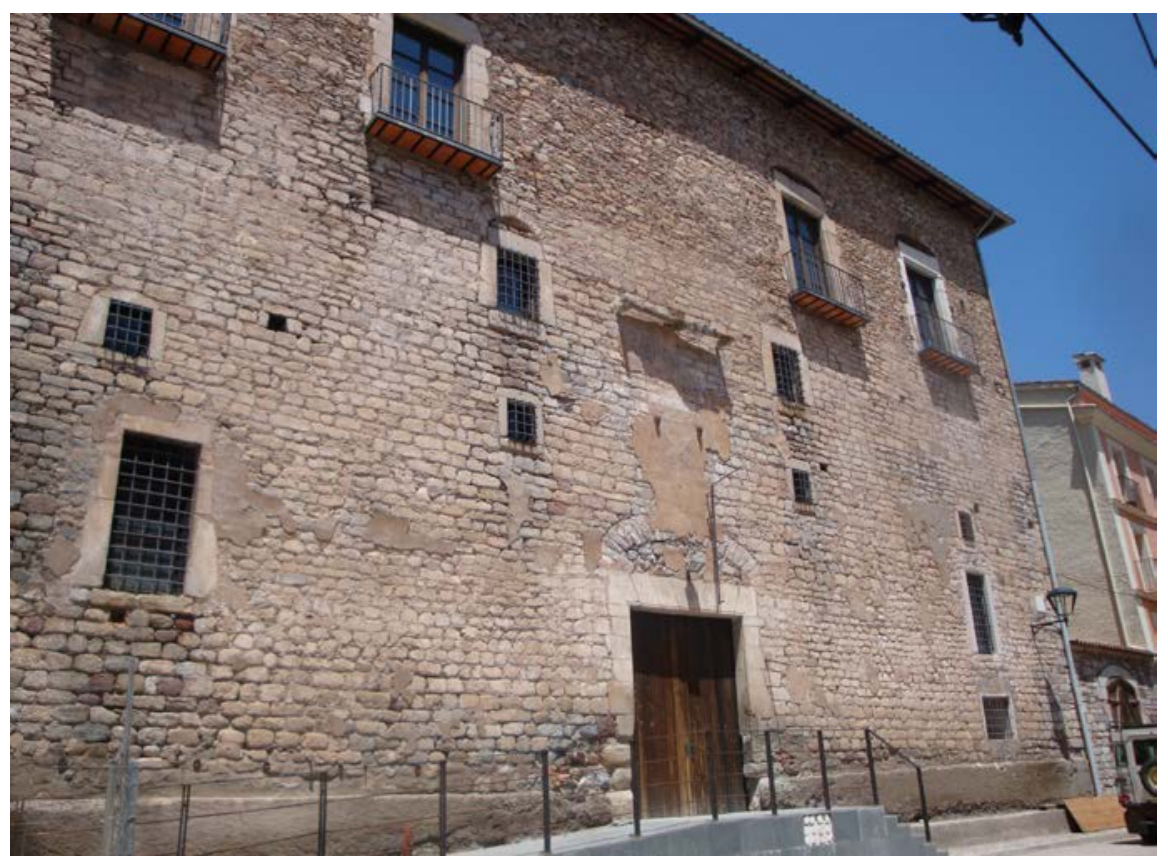

Fotografia 2. Lonja de la Sal, de Gerri de la Sal

\subsection{Parada 2 - CONDICIONAL. MINA DE MANGANÉS DE LA MANRESANA, (Arboló, terme municipal de Gerri de la Sal, Baix Pallars, comarca del Pallars Sobirà). (Full 214).}

Des de la parada anterior, cal fer un breu recorregut cap al Nord, tot seguint per la carretera nacional N-260 (coincidint aquí amb la C-147). En sobrepassar el poble de Compte s'arribarà al trencall del Santuari d'Arboló, cap on cal anar. Més amunt, anant sempre a peu, s'arribarà a l'antiga mineta de manganès on cal fer la present aturada, a uns $3 \mathrm{Km}$ de l'anterior.

En aquest recorregut inicialment hem anat trobant els materials triàsics del Keuper, ja esmentats a la parada anterior. Cal recordar que aquests materials formen part del Mantell de les Nogueres. Més endavant, entre Compte i Arboló hem trobat afloraments dels materials paleozoics del Devonià.

Precisament, en aquest indret hi ha un aflorament dels nivells de les roques carbonatades del Devonià i entre elles hi ha una mineralització manganesífera associada a rebliment de cavitats d'origen kàrstic. Entre els minerals presents hi ha: PIROLUSITA, BIRNESSITA, PSILOMENANA, MANGANITA, TODOROQUITA, MANGANOCALCITA i RODOCROISITA. Tanmateix hi ha mineralitzacions de ferro amb GOETHITA i HEMATITES. També hi ha present la CALCITA, molt abundant. 


\subsection{Parada 3 - CONDICIONAL. MINA D'HULLA D'ESTAC, (antic terme d'Estac i ara del terme municipal de Sort, comarca del Pallars Sobirà). (Full 214).}

Des de la parada anterior, cal fer un breu recorregut cap al Nord, tot seguint per la carretera nacional N-260 (coincidint aquí amb la C-147). En sobrepassar Baró, ens convindrà seguir cap a Sort, fins trobar per l'esquerra el trencall d'Estac, que haurem d'agafar. A uns $2 \mathrm{Km}$ de I'inici de la carretera trobarem un camí que ens durà cap a l'antiga mina on farem la present aturada, a uns $8 \mathrm{Km}$ de l'anterior.

En aquest recorregut inicialment hem anat trobant els materials paleozoics del Devonià $\mathrm{i}$ posteriorment els del Carbonífer, segons els llocs. Aquests materials formen part del Mantell de les Nogueres, on ara som.

Aquests darrers són els que es troben a l'indret de la present aturada. Aquí, precisament hi havia una mineta, en la que es van intentar aprofitar els nivells carbonosos (hulles) del carbonífer, sense gaire èxit.

\subsection{Parada 4. FORN DE GUIX DEL CEMENTIRI, (terme municipal de Sort, comarca del Pallars Sobirà). (Full 214).}

Des de la parada anterior, cal fer un breu recorregut cap al Nord, tot seguint per la carretera nacional N-260 (coincidint aquí amb la C-147). En sobrepassar el Cementiri de Sort, caldrà fer una nova aturada, a menys de $6 \mathrm{Km}$ de l'anterior.

En aquest recorregut inicialment hem anat trobant els materials que formen part del Mantell de les Nogueres. Així, inicialment fins arribar a Montardit haurem trobat afloraments dels materials paleozoics del Devonià i del Carbonífer, segons els llocs. Finalment, entre Montardit i Sort haurem tornat a trobar afloraments dels materials triàsics del Keuper.

Precisament, en aquest indret hi ha un aflorament dels nivells de guixos triàsics del Keuper, els quals va ésser utilitzats com a matèria prima per a un forn de guix proper. Pel que fa a aquest forn de guix, cal dir que aquest es troba en bon estat de conservació, tot i que caldria realitzar tasques de manteniment.

\subsection{Parada 5. FORN DE CALÇ DE SORT, (terme municipal de Sort, comarca del Pallars Sobirà). (Full 214).}

Després de realitzar la parada anterior, cal seguir cap a la població de Sort. Just quasi abans d'arribar-hi, caldrà fer la darrera aturada, per la carretera N-260 (la qual coincideix aquí amb la C-147). A l'entrada de la població, al costat de l'antic forn de calç, farem aquesta aturada.

La població de Sort es troba situada dintre del Mantell de les Nogueres, entre afloraments dels materials triàsics del Keuper.

Pel que fa al forn de calç, cal dir que constitueix un bon exemple d'aquests sistemes d'aprofitament dels materials carbonatats, de cara a l'obtenció de calç. En aquest cas s'utilitzaven els afloraments carbonatats del triàsic. (fotografia 3 ). 


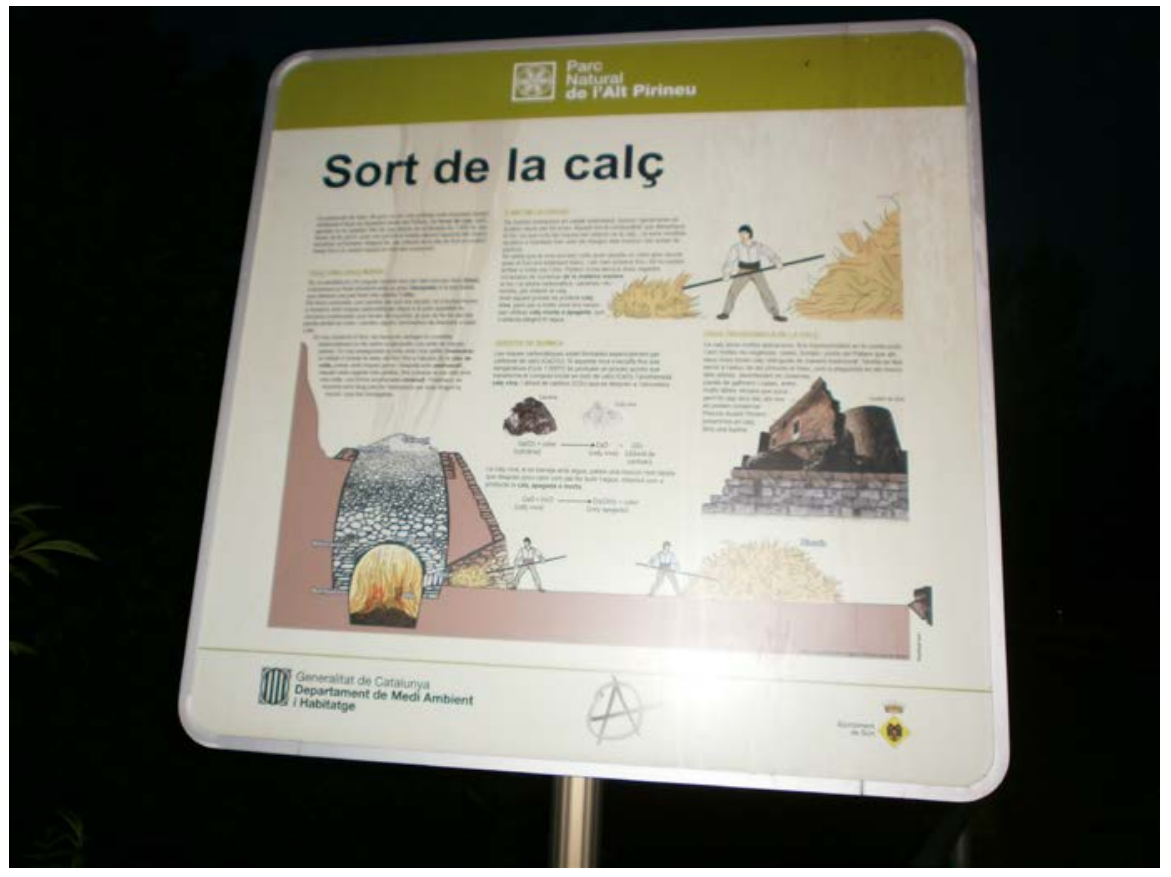

Fotografia 3. Cartell explicatiu del Forn de Calç de Sort

En aquest indret finalitza el recorregut de l'itinerari

\section{Bibliografia}

GUIMERÀ, J. et altri (1992).- Geologia (II), Història Natural dels Països Catalans, Vol. 2, 547 pag. Enciclopèdia Catalana, S.A. Barcelona.

IGME (1970).- Mapa Geológico de España, a escala 1.200.000 (Síntesis de la Cartografia existente). Full i memòria nº 24, Berga. Inst. Geol. Minero de España. Madrid.

IGME (1994).- Mapa Geológico de España a escala 1:50.000 (Plan Magna). Fulla i Memòria $\mathrm{n}^{\circ}$ 252 (Tremp). Inst. GeoMinero y Tecnol. España. Minist. Indústria. Madrid.

MATA-PERELLÓ, J.M. (1991).- Els Minerals de Catalunya. Arxius de la Secció de Ciències de I'Institut d'estudis Catalans, vol.47, 545 pàgines. Barcelona.

MATA-PERELLÓ, J.M. (1995a).- Itinerari Geològico-Mineralògic pel Pallars Jussà i pel Pallars Sobirà: des de Puimanyons a Sort. Inèdit, 13 pàgines. Barcelona.

MATA-PERELLÓ, J.M. (1995b).- Itinerari Geològico-Mineralògic pels dos Pallars: de la Pobla de Segur a Senterada. Inèdit, 10 pàg. Manresa.

MATA-PERELLÓ, J.M. (1995c).- Itinerari Geològico-Mineralògic pel Pallars Sobirà i per I'Alt Urgell: des de Gerri de la Sal a Sort i a Castellàs. Selecció d'itineraris, it. 14. pp. 131-138. Manresa. 
MATA-PERELLÓ, J.N. (1996a).- Sortida de recerca geològica i mineralògica pels dos Pallars: des del $\mathrm{Pas}$ de Terradets al Pas de Collegats. Inèdit, 12 pàgines. Manresa.

MATA-PERELLÓ, J.M. (1996b).- Recerca geològica i mineralògica pel Pallars Jussà i pel Pallars Sobirà: des de la Pobla de Segur a Montcortés i a Gerri de la Sal. Inèdit, 12 pag. Manresa.

MATA-PERELLÓ, J.M. (1996c).- Recerca geològica i mineralògica pels dos Pallars: des del Pas de Collegats a Gerri de la Sal. Inèdit, ,13 pàg. Manresa.

MATA-PERELLÓ, J.M. (1996d).- Circuït-itinerari de recerca geològica i mineralògica per I’Alt Urgell i pel Pallars Sobirà: des de la Palanca de Noves al Coll de Cantó i a la Palanca de Noves. Inèdit, 16 pag. Manresa.

MATA-PERELLÓ, J.M. (1998).- Recerca Geològica i Mineralògica per les comarques del Pallars Jussà i pel Pallars Sobirà: des del Congost d'Erinyà a la Plana de Mont-rós, i des Gerri de la Sal al Coll de Cantó, revista Algeps, no 98, 14 pag. Manresa.

MATA-PERELLÓ, J.M. (2002).- Recerca geològica i mineralògica per la comarca del Pallars Sobirà: des del Gerri de la Sal i Montcortés a Sort i a Esterri d’Àneu. Inèdit. 12 pàgines. Manresa.

MATA-PERELLÓ, J.M. (2009a).- Recerca geològica i mineralògica per la comarca del Pallars Sobirà: des del Gerri de la Sal a Sort i a Esterri d’Àneu. . Inèdit. 10 pàgines. Manresa.

MATA-PERELLÓ, J.M. (2009b).- Recorregut de recerca geològic i mineralògica per les terres dels dos Pallars: des de la Pobla de Segur cap a Collegats, Gerri de la Sal, Estac i a Sort. 10 pàgines. Manresa.

MATA-PERELLÓ, J.M. (2012).- Recerca geològica i mineralògica per la comarca del Pallars Sobirà: des del Gerri de la Sal a Sort i a Llavorsí. Inèdit 10 pàgines. Manresa.

MATA-PERELLÓ, J.M i SANZ BALAGUÉ, J. (1993).- Guia de Identificación de Minerales, Edit Parcir. 215 pàgines. Manresa.

RIBA ARDERIU, O. et altri (1976).- Geografia Física dels Països Catalans. Edit Ketres. Barcelona.

ROSELL SANUI, J. (1970).- Explicació del Mapa Geològic, a escala 1:50.000, corresponent al full n 252 (Tremp). Mapa Geológico de España. Inst. Geológico y Minero de España. Madrid.

SGC (1990).- Mapa Geològic de Catalunya a escala 1:250.000, Servei Geològic de Catalunya (Inst. Cartograf. de Catalunya). Barcelona. 